\title{
Methodological approach to study the dynamics of production networks: discrete-event simulation modelling
}

\author{
Salvatore Cannella* \\ Centre for Management Studies of Instituto Superior Técnico, \\ Technical University of Lisbon, \\ Av. Prof Cavaco Silva, 2780-990, Porto Salvo, Portugal \\ E-mail: salvatore.cannella@ist.utl.pt \\ *Corresponding author
}

\section{Manfredi Bruccoleri}

Department of Chemical, Management, Mechanical Engineering and Computer Science, Università degli Studi di Palermo,

Viale delle Scienze, Ed. 8, 90128, Palermo, Italy

E-mail: manfredi.bruccoleri@unipa.it

\section{Ana Paula Barbosa-Póvoa and Susana Relvas}

Centre for Management Studies, Instituto Superior Técnico, Technical University of Lisbon, Av. Prof Cavaco Silva, 2780-990, Porto Salvo, Portugal E-mail: apovoa@ist.utl.pt E-mail: susana.relvas@ist.utl.pt

\begin{abstract}
This paper shows how discrete-event simulation represents an appropriate tool for approaching the dynamics of production networks. Three important factors influencing production network dynamics, specifically finite production capacity, manufacturing lead time, and its variability are discussed and a basic discrete-event simulation model is presented. Such model, which in its basic form represents a simple retail/distribution two-stage supply chain, is then extended in order to take into account those factors that can not be included in a classical control theoretical model.
\end{abstract}

Keywords: supply chain dynamics; demand amplification; discrete-event simulation; manufacturing lead-time.

Reference to this paper should be made as follows: Cannella, S., Bruccoleri, M., Barbosa-Póvoa, A.P. and Relvas, S. (2013) 'Methodological approach to study the dynamics of production networks: discrete-event simulation modelling', Int. J. Logistics Systems and Management, Vol. 16, No. 2, pp.211-223.

Biographical notes: Salvatore Cannella is currently a Researcher at the Technical University of Lisbon, Portugal. He holds a Doctor Europaeus' degree in Logistics and Management for Quality, Sustainability and Safety from the 
University of Palermo, Italy, in co-tutoring agreement with the University of Seville, Spain. His research focuses on supply chain management, the bullwhip effect and assessment for quality in the European space of higher education.

Manfredi Bruccoleri is an Associate Professor at the Faculty of Engineering of the University of Palermo and he teaches business process management and operations management. His research interests focus on open innovation, business process reengineering, behavioural operations, supply chain management, manufacturing strategy and networking strategy. He is the author and co-author of about 70 international scientific papers. He is a member of the Italian Association of Mechanical Technology (AITEM), of the Italian Association of Management Engineering (A.i.I.G.), European Operations Management Association (EUROMA), Production \& Operations Management Society (POMS).

Ana Paula Barbosa-Póvoa obtained her $\mathrm{PhD}$ in Engineering from Imperial College of Science Technology and Medicine. She is currently a Full Professor of Operations and Logistics at the Department of Engineering and Management of Instituto Superior Técnico (IST), Technical University of Lisbon, Portugal. Her research interests are on the supply chain management, where both forward and reverse structures are included and on the design, planning and scheduling of flexible systems. She has published widely in these areas and supervised several Master and $\mathrm{PhD}$ students.

Susana Relvas obtained her PhD in Industrial Engineering and Management from Instituto Superior Técnico (IST) at the Technical University of Lisbon, Portugal. She is an Assistant Professor at the Department of Engineering and Management of IST and lectures courses on logistics, supply chain management and operations management. Her main research interests are oil supply chain management, general supply chain management and logistic activities.

\section{Introduction}

The analysis of supply chain dynamics mainly refers to the study of the well-acknowledged bullwhip effect (BE), i.e., the phenomenon in which the variability of the demand orders in a supply chain is magnified as the orders move up to the supply chain (Lee et al., 1997). Besides the BE research stream aimed at giving empirical evidence of the existence of this phenomenon in real supply chains (Hammond, 1994; Lee et al., 1997; Cachon and Fisher 1997, de Kok et al., 2005) most of the scientific work in supply chain dynamics concerns pure retail/distribution few-stages chains. The main reason for this is probably imputable to the fact that such a research topic is mostly approached in an analytical fashion by adopting continuous time differential equation models, discrete time difference equation models and classical operational research methods.

The scientific and industrial knowledge on supply chain dynamics, which has been created, since '50, (Simon, 1952; Vassian, 1955; Magee, 1958; Forrester, 1961) by the adoption of these approaches, is indisputable. However, although adopting simplifying assumptions makes possible the realisation and resolution of analytical models, on the other side it often makes the model outlying from reality when applying these approaches 
to the analysis of production networks (Campuzano and Mula, 2011). Essentially, the traditional analytical models are no always able to cope with the characteristics of dynamics, and uncertainty of the supply chain networks (Long et al., 2011; Domínguez et al., 2012). On the contrary, many key elements and variables characterising the production network which are usually not considered in a pure retail/distribution few-stages chains like manufacturing lead time uncertainty, limited capacity of the production stage, vertical and horizontal extension of the supply chain, BOM structure of the products, etc., cannot be disregarded. Thus, simulation modelling method can play a crucial role in advancing knowledge in this area, where mathematical modelling cannot accommodate the associated dynamic complexity (Syntetos et al., 2011).

The present paper wishes to illustrate advantages of non-analytical approaches, as discrete event simulation (DES), when analysing demand amplification issues in production networks. In particular, some production network crucial aspects are investigated like the impact of the manufacturing lead time and its variability and the production capacity of the manufacturing stage on its dynamics.

The paper is articulated as follows. Section 2 presents a brief overview on supply chain dynamics research. Section 3 reports some interesting results arising from a study conducted by the authors when analysing production network dynamics by adopting non-analytical methodologies. Section 4 presents discussions and managerial implications. Conclusions and future remarks are reported in the last section.

\section{Supply chain dynamics: research methodologies and DES}

As already mentioned the analysis of supply chain dynamics mainly refers to the study of the BE. The BE is not a new supply chain phenomenon, different BE aspects have been explored and different research methodologies for approaching it have been adopted by researchers.

Schmenner (2001) provides an historical overview of the problem, including a discussion on how Procter \& Gamble has been concerned with bullwhip since at least 1919. In last decade, an increasing attention has been devoted to the phenomenon and to its deleterious consequences. Several issues have been investigated within the BE and supply chain field such as: reverse logistic (Zhou and Disney, 2006), multi-product (Reichhart et al., 2008), stochastic lead times (Boute et al., 2007), capacity constraints (Yuan and Ashayeri, 2009), flexibility (Jain et al., 2009; Hanna et al., 2010), batching (Potter and Disney, 2006; Hussain and Drake, 2011), collaboration (Matopoulos et al., 2007; Darwish and Goyal 2011; Sujatha, 2011), order policies (Azadeh et al., 2011; Cannella et al., 2011), pricing (O'Donnell et al., 2009), and performance measurement (Wong and Wong, 2008; Keebler and Plank 2009; Pettersson and Segerstedt, 2011) amongst others. Analogously, several studies have addressed the methodological approaches to study the dynamics of supply chains (Riddalls et al., 2000; Kleijnen and Smits, 2003; Dejonckheere et al., 2004; Holweg and Disney, 2005; Geary et al., 2006; Ashayeri and Lemmens, 2006, Towill et al., 2007; Disney and Lambrecht, 2008; Nilakantan, 2010; Ciancimino and Cannella, 2011; Lättilä, 2011; Scholz-Reiter et al., 2011). The revision of the methods available to study the BE reveals that the continuous time differential equation models, the discrete time difference equation models, and the classical operational research methods represent the standard methodological approaches within the BE academic and practitioner worlds. 
On the contrary, DES, while being largely used by decision makers, is poorly used by academicians for capturing supply chain dynamics. However, as reported by Disney and Lambrecht (2008), DES actually has the power to investigate, at least numerically, very realistic models of supply chains. It is possible to explicitly model such things as capacity constraints, non-negative inventory and WIP levels, actual real-life demand patterns, process uncertainties (machine breakdowns), quality losses, process time variation, rework and even quality control procedures. According to van der Vorst et al. (2009) the key contribution of DES lies in its capability of modelling and trading off elementary uncertainties underlying product quality, and chain logistics, as well as their interaction. Furthermore, DES is useful in the detailed design of the cyclic planning and control structure (Pool et al., 2011). Basically, DES enables companies to perform powerful what-if analyses leading them to better planning decisions, allowing the comparison of various operational alternatives without interrupting the real system and permit time compression so that timely policy decisions can be made. In this paper, we wish to show how DES can be a powerful tool for studying not necessary very complex models (like real supply chain models) but also simple models that, although being simple, can not be approached by analytical approaches.

\section{Production network dynamics: a practitioner non-analytical analysis}

In this section, we wish to show how, in practice, not considering some of the already mentioned factors that characterise the production network could bring to incomplete analysis and to not understand the real holistic nature of supply chain dynamics. The methodology, which is here proposed for the production network analysis, uses non-analytical tools as DES for studying specific production network scenarios. In this sense, no mathematical relations will be assessed between those factors and the demand amplification phenomenon, but only 'insight sketches' are illustrated and evidenced.

\subsection{The basic supply chain model}

The supply chain here considered is a three-stage supply chain (Figure 1) where each actor satisfies the demand of its downstream actor in a make to stock basis.

The ordering policy of each actor of the chain is the classical order up to policy (OUT) based on exponential smoothing demand forecast. In other words, each period the generic actor $i$ orders a quantity equal to (Dejonckheere et al., 2003):

$$
Q_{t}^{i}=S_{t}^{i} \text {-inventory position }{ }_{t}^{i}
$$

where $Q_{t}^{i}$ is the ordering decision made at the end of period $t, S_{t}^{i}$ is the order-up-to level used in period $t$ and the inventory position equals net stock $I N V_{t}^{i}$ (inventory on hand minus backlog) plus on order $W I P_{t}^{i}$, as explicated in equation (2).

$$
Q_{t}^{i}=\max \left\{\left(L T^{i}+1\right) \cdot \hat{D}_{t}^{i}-\left(I N V_{t}^{i}+W I P_{t}^{i}\right) ; 0\right\}
$$

$\hat{D}_{t}^{i}$ is the forecasted demand, $L T$ is the lead time and factor 1 takes into account that, in the sequence of events, if the $i^{\text {th }}$ stage of the supply chain orders a quantity at the end of 
period $t$ and LT is equal tozero, the order is received in period $t+1$. Also, the demand forecast is calculated as in equation (3).

$$
\hat{D}_{t}^{i}=\alpha \cdot D_{t}^{i}+(1-\alpha) \cdot \hat{D}_{t-1}^{i}
$$

Figure 1 A three-stages supply chain (see online version for colours)

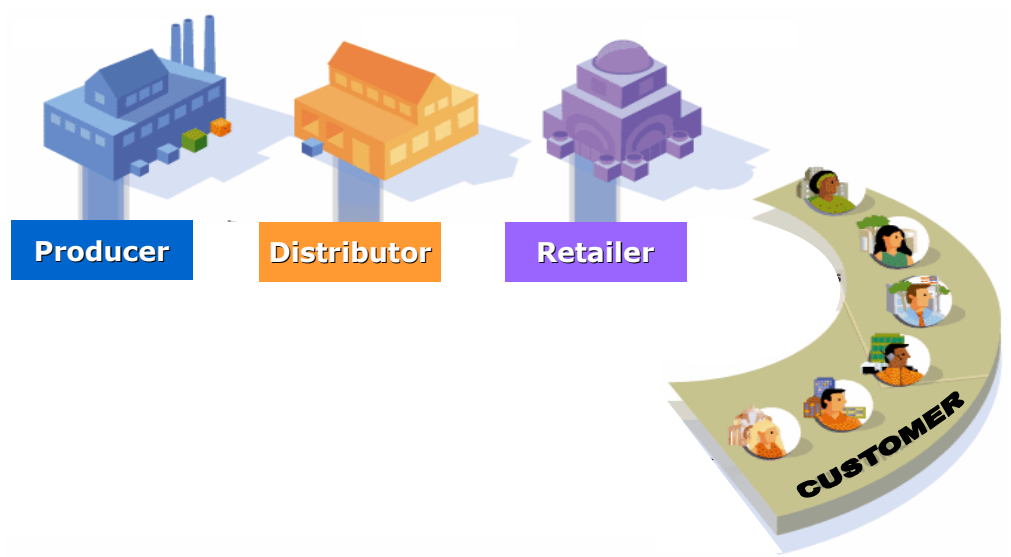

The sequence of actions that the $i^{\text {th }}$ actor of the distribution stages (in this case both the retailer and the distributor) performs each time period is described in the following:

1 the actor receives goods previously ordered

2 the actor observes and satisfies actual demand; if inventory level is not enough, unfilled demand is backlogged

3 the actor forecasts the next expected demand

4 the actor observes the inventory position and evaluates if an order should be placed to the actor upstream in the supply chain

5 the actor orders a quantity $Q_{t}$ of goods to the actor upstream in the supply chain (its supplier) according to equation (2).

For each actor a discrete event model has been developed according to the Arena ${ }^{\circledR} 5.0$ standards.

As an example, Figure 2 depicts a sketch of the Arena ${ }^{\circledR}$ model of the Retailer actor. The simulation model is composed by some Arena ${ }^{\circledR}$ logical blocks, which implement the above listed sequence of events and actions of the retailer process during demand satisfaction and order submitting. Next a detailed analysis is made on the Arena ${ }^{\circledR}$ logical blocks of Figure 2.

The CREATE block is used to generate at the end of every time period a logical entity which will flow throughout the process and activate the subsequent blocks.

The ASSIGN 1 block is used to model equations (2) and (3). Thus, once the logical entities such a block, $\hat{D}_{t}^{\text {retailer }}$ and $Q_{t}^{\text {retailer }}$ are calculated.

The following SEPARATE block is used only for duplicating the logical entity into $Q_{t}^{\text {retailer }}$ number of entities which, from now on, represent the physical goods that the retailer decides to order. 
Once the order is generated, the following step consists in updating the number of goods in the retailed order and the inventory on hand of the distributor according to the following equations:

$$
\begin{aligned}
& W I P_{t}^{\text {retailer }}=W I P_{t-1}^{\text {retailer }}+Q_{t}^{\text {retailer }} \\
& I N V_{t}^{\text {distributor }}=I N V_{t-1}^{\text {distributor }}-Q_{t}^{\text {retailer }}
\end{aligned}
$$

Figure 2 The arena ${ }^{\circledR}$ model of the retailer stage

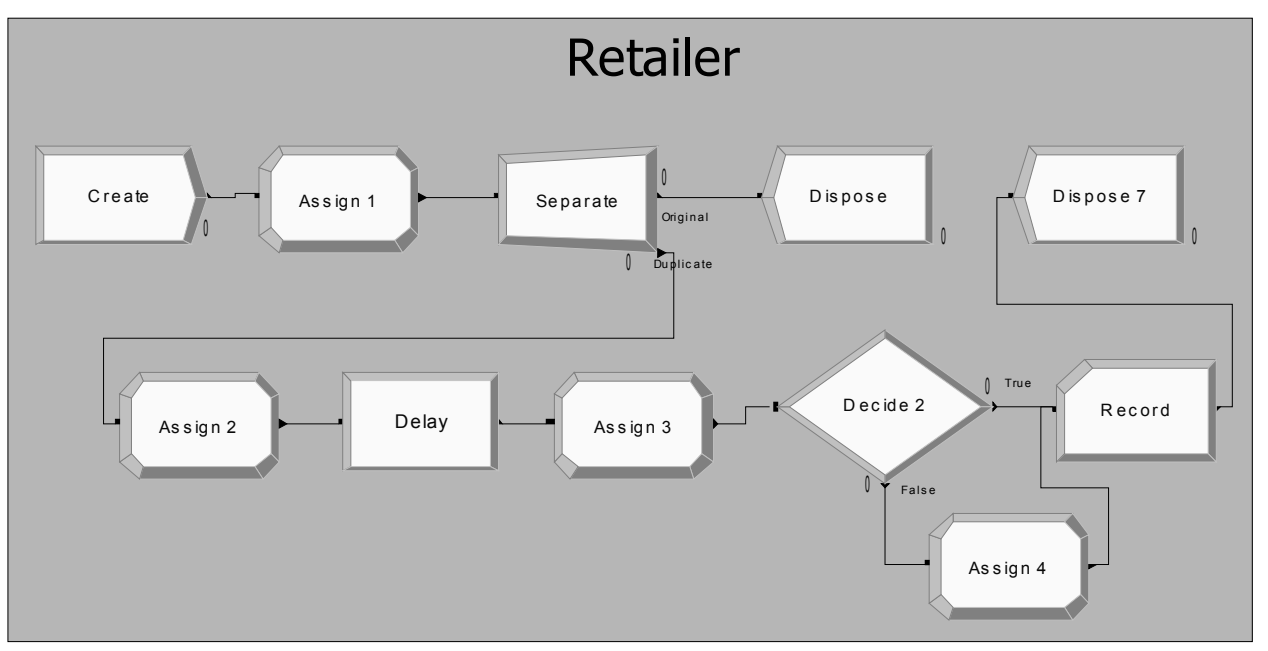

Such activity is performed by the ASSIGN 2 block. Notice that actually, variable $I N V_{t}^{\text {distributor }}$ could result to be minor than zero. This would means that the distributor stage was not able to supply the whole quantity required by the retailer and thus a part of it will be backlogged (DECIDE 2 and ASSIGN 4 blocks).

The next activity is modelled by a DELAY block where the circulating entities are delayed by an interval of time equal to the lead time.

After this delay, the ASSIGN 3 block updates the net stock of the retailer, as described in equations (6) and (7).

$$
\begin{aligned}
& W I P_{t}^{\text {retailer }}=W I P_{t-1}^{\text {retailer }}-Q_{t-L T}^{\text {retailer }} \\
& I N V_{t}^{\text {retailer }}=I N V_{t-1}^{\text {retailer }}+\min \left\{Q_{t-L T}^{\text {retailer }} ; \max \left[I N V_{t-L T}^{\text {distributor }} ; 0\right]\right\}
\end{aligned}
$$

Notice that equation (7) considers that the inventory level of the retailer stage (the same happens for the distribution stage) is incremented each period by a quantity, which is the minimum between the quantity that the same stage had ordered one LT before and the quantity that was available during that period in the inventory on hand of its supplier.

\subsection{Finite production capacity of the manufacturing stage}

Adding into the model information on the limited production capacity of the manufacturing stage could strongly increase the complexity of the model. Indeed, according to the level of abstraction that the model should have, one would like to model 
the whole manufacturing process, including manufacturing resources, product routings, machine failures, queues, blocking and starving events, etc. However, production systems flow analysis taking into account such elements is a typical object of study of manufacturing systems DES models this is out of the scope of the present paper. On the contrary, at this phase of the study we are interested in considering the manufacturing stage as a black box with a maximum production rate (production capacity), i.e., with a maximum number of products that it is able to offer within each period. In this case, it would not be a mistake to model the manufacturing stage as a buffer, which is updated each period to a quantity equal to production capacity and then decreased by the distributor order. Also, the distribution stage should be modelled as it was described in Section 3.1 except for equation (7), which, in turns, becomes:

$$
I N V_{t}^{\text {distributor }}=I N V_{t-1}^{\text {distributor }}+\min \left\{Q_{t-L T}^{\text {distributor }} ; C_{p}\right\}
$$

where $C_{p}$ represents the fixed capacity of the producer. Notice that the described model can be considered correct only if the producer stage produces its product on a make-to-stock basis - this represents a very important consideration at this point. Indeed, the finite product buffer of the production stage is refilled according to equation (2). As it can be easily expected, in order to satisfy the final customer demand, the production capacity should be bigger then the average demand.

\subsection{Manufacturing lead time}

According to the modelling assumption about the production stage that has been declared in the previous section, when modelling the producer stage, almost the same Arena blocks as in Figure 2 should be used. Indeed, the producer model behaves as a distribution stage even if an important difference arises due to the introduction of the manufacturing lead time (MLT) into equation (2).

Keeping still valid the hypothesis that the producer stage adopts a make-to-stock policy, according to the OUT policy, the quantity of goods that the producer stage of the supply chain $Q_{t}^{\text {producer }}$ launches into its production system depends on the MLT itself. Indeed, the lead time of the producer, instead of the order processing time and the shipping time, should take into account the actual manufacturing lead time. MLT refers to the elapsed time between launching a production order and receiving it from the production system. In real supply chains, MLT is not a constant and depends on many factors such as the order quantity and the productions system congestion. Indicating with $T c$ the theoretical cycle time of the manufacturing system $\left(T c=1 / C_{p}\right)$, the minimum value that can get the MLT for a given order $Q_{t}^{\text {producer }}$ can be calculated as:

$$
\operatorname{MLT}\left(Q_{t}^{\text {producer }}\right)=\left(\text { IIP }_{t}^{\text {producer }}+Q_{t}^{\text {producer }}\right) \cdot T c
$$

Substituting this value to LT of equation (2), it comes out that the quantity of goods that the producer 'orders' to its manufacturing system at time $t$ is:

$$
Q_{t}=\max \left\{\left[\left(W I P_{t} \cdot T c+1\right) \cdot \hat{D}_{t}-\left(I N V_{t}+W I P_{t}\right)\right] \cdot \frac{1}{1-T c \cdot \hat{D}_{t}} ; 0\right\}
$$


Looking at equation (10), it can be seen that according to the OUT policy, the more the forecasted demand draws up the production system capacity (expressed as $C_{p}=1 / T c$ ) the bigger the production order will be. In theory, when the two values are equal, the production order tends to infinite as showed in Figure 3.

Also, if the forecasted demand is bigger than the production capacity, equation (10) does not make sense due to the fact that in this case the producer could never supply the required quantity.

Finally, if $T c$ is theoretically equal to zero (infinite production capacity) equation (9) become the same as equation (2) [remember that in this case the producer is 'ordering' to its production system and this means that shipping and processing lead time are zero, i.e., $L T=0$ in equation (2)].

Figure 3 Producer order quantity according to the order up policy

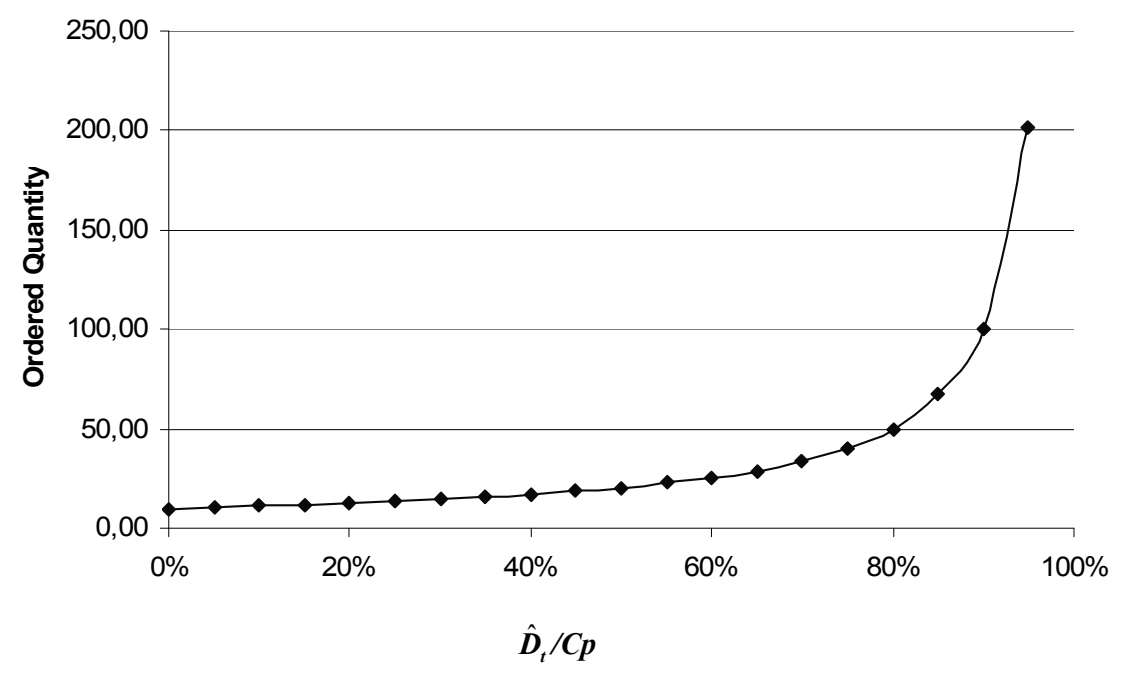

\subsection{Lead time variability}

Considering lead times as constant appears as quite unrealistic in supply chains and it may even conduct to partial evaluations of supply chain performance. As the reader has noticed in the previous sections, the quantity to order, for instance, can depends on the lead times and thus considering lead times as constant may bring to incomplete decisions. Some works about non-constant lead times have treated it as a stochastic variable. For instance Kaplan (1970) has considered lead time as a discrete random variable and has developed a finite horizon model that allows obtaining an optimal inventory policy that depends on ordering costs. De Kok (1993) has treated lead time as a distributed random variable but dependent on the customer demand. Moreover, if is it true that in Section 3.3 we have considered variability of the lead time (only the manufacturing lead time) because it depends on the ordered quantity, it is also true that the variability of lead times in supply chains has other two motivations: an endogenous one and an exogenous one. The endogenous variability is due to the variability of the activities of the chain, such as production times that have an uncertainty component. The exogenous variability is due to 
managers that tend to reduce lead times in order to gain better performance. Thus, lead time, is not constant and it can be expressed by the following equation:

$$
L T_{t}=\frac{Q_{t}}{K}+\varepsilon
$$

$L T_{t}$ is the lead time at time $t, Q_{t}$ is the quantity of goods that have been ordered by the chain actor at time $t ; \varepsilon$ is an erratic factor that takes into account uncertainty; $K$ is a constant which represents the production capacity $C_{p}$ in case the lead time represents the MLT, but also other factors such as the maximum number of transportable goods within a week if the lead time represents a shipping time. A simulation case study which was conducted by Sabato and Bruccoleri (2005) showed that considering lead time as a constant would lead to underestimate the BE on about $30 \%$ even if this value depends on the level of LT variability and, of course on the specific supply chain structure that they analysed. Anyway, they showed that in some cases, it would result more profitable for managers to reduce lead time variability than lead time average value or, more generally, reducing lead time can lead to a better performance only if this reduction will not causes an increase in lead time variability, that is managers must pay attention in lead time reduction if this reduction introduces uncertainty. This result was recently confirmed by the study of Chaharsooghi and Heydari (2010). Their findings confirmed that the effect of lead time variance on supply chain performance measures is greater than the effect of the lead time mean. It is imperative to underline that Chaharsooghi and Heydari (2010) analysed a four-echelon supply chain via discrete time modelling and adopted MATLAB as simulation tool. Even if in other works (Sabato and Bruccoleri, 2005; Sabato et al., 2004), the above DES basic model (Subsection 3.1) has been already tested and validated by verifying that the obtained results are coherent to those achieved by Chen et al. (2000) and Dejonckheere et al. (2003), the results of Chaharsooghi and Heydari (2010) support the validation of the presented lead time variability modelling.

\section{Discussion and managerial implications}

As stated by Holweg and Disney (2005) there is still a range of unsolved research questions in supply chain and BE. The authors argue that the key reason is related to the non-linearities found in real-life supply chains (constrained capacities and lost sales) and the high order of differential equations (one tier generally gives a 2 nd to 4 th order system; 2 tiers even 2 nd to 6 th order) makes analytical analysis difficult.

The scenarios presented in this paper show how those obstacles can be overshadowed and several assumptions of the real-life supply chains can be considered by adopting DES. We have provided an overview of how a multi-echelon supply chain can be simulated under different assumptions, by presenting the mathematical formalisation and the Arena's instructions. The modelling of the manufacturing lead time variability and of the production capacity of the manufacturing stage in a multi-echelon supply chain, may also serve to reassert how DES is a suitable method of capturing the dynamic nature of modern SC design and operation (Byrne et al., 2010) and of understanding issues of supply chain decision making (Almeder et al., 2009). We expect that both researchers and practitioners would benefit from the presented models. Practitioners can use the above-illustrated techniques for generation and testing of ad-hoc supply chain strategies. 
For instance, by using probability distribution, unexpected events in certain areas like in the final customer demand pattern can be modelled and the impact of these events on the supply chain can be understood. Also, the flow of parts within the manufacturing systems of the producer stages of the supply chain could be studied. Moreover variability intrinsic to order processing time, or shipping time, or even manufacturing lead time could be considered. Researchers could address unsolved research questions in supply chain and $\mathrm{BE}$, such as two of the potential topics for future investigation in this area recently identified by Disney and Lambrecht (2008): e.g., multi-product scenarios and stochastic lead times

\section{Conclusions}

DES as a research methodology is not an innovative tool nor it represents the new frontier for approaching studies in supply chain. However, it seems that DES can help researchers and practitioners to overcome some limitation imposed by the analytical approach. The paper presented how a basic DES model can be built and how to introduce in the model some important aspects that are not usually considered in the classical BE literature. More specifically, we presented how to model the production capacity of the manufacturing stage, the manufacturing lead time and its variability in a multi-echelon supply chain. Furthermore, we reported some considerations arising from the possibility of using DES for supply chain dynamics analysis. One of the benefits that come from this paper lies in the formalisation of the Arena's instructions that can be used to model the above-mentioned assumptions of the real-life supply chains. By doing so, a solution was proposed to overcoming the main drawbacks of the analytical modelling for supply chain dynamics analysis. The presented models may serve as staring points to fill several advocated gaps in supply chain analysis and BE evaluation. A limitation of this work, as well as the limitation of any DES simulation models, lies in the absence of a succinct descriptive language for their formulation. According to Riddalls et al. (2000) this is a direct result of the lack of a commonly accepted theoretical framework analogous to the rigorous basis provided by calculus. Future efforts should be dedicated to develop and validate basic DES models that are not context-specific (in order to maintain a medium level of abstraction of the model) and could be reused as valid test-bed for theoretical (not too much practitioner) academic production network studies.

\section{Acknowledgements}

We wish to thank Professor Angappa Gunasekaran and the anonymous referees for their insightful comments on earlier versions of the paper. This research was funded by a grant from the Portuguese Foundation for Science and Technology, grant SFRH/BPD/68576/2010.

\section{References}

Almeder, C., Preusser, M. and Hartl, R.F. (2009) 'Simulation and optimization of supply chains: alternative or complementary approaches?', OR Spectrum, Vol. 31, No. 1, pp.95-119. 
Ashayeri, J. and Lemmens, L. (2006) 'Economic value added of supply chain demand planning: a system dynamics simulation', Robotics and Computer Integrated Manufacturing, Vol. 22, Nos. 5-6, pp.550-556.

Azadeh, A., Allahverdiloo, M. and Shirkouhi, S.N. (2011) 'A computer simulation model for analysing performance of inventory policy in multi-product mode in two-echelon supply chain', International Journal of Logistics Systems and Management, Vol. 8, No. 1, pp.66-85.

Boute, R., Disney, S.M., Lambrecht, M. and Van Houdt, B. (2007) 'An integrated production and inventory model to dampen upstream demand variability in the supply chain', European Journal of Operational Research, Vol. 178, No. 1, pp.121-142.

Byrne, J., Heavey, C. and Byrne, P.J. (2010) 'A review of web-based simulation and supporting tools', Simulation Modelling Practice and Theory, Vol. 18, No. 3, pp.253-276.

Cachon, G. and Fisher, M. (1997) 'Campbell soup's continuous replenishment program: evaluation and enhanced inventory decision rules', Production and Operations Management, Vol. 6, No. 3, pp.266-276.

Campuzano, F. and Mula, J. (2011) Supply Chain Simulation: A System Dynamics Approach for Improving Performance, 1st ed., Springer-Verlas, London.

Cannella, S., Ciancimino, E. and Framinan, J.M. (2011) 'Inventory policies and information sharing in multi-echelon supply chains', Production Planning \& Control, Vol. 22, No. 7, pp.649-659.

Chaharsooghi, S.K. and Heydari, J. (2010) 'LT variance or LT mean reduction in supply chain management: which one has a higher impact on SC performance?', International Journal of Production Economics, Vol. 124, No. 2, pp.475-481.

Chen, F., Drezner, Z., Ryan, J.K. and Simchi-Levi, D. (2000) 'Quantifying the bullwhip effect in a simple supply chain: the impact of forecasting, lead-times and information', Management Science, Vol. 46, No. 3, pp.436-443.

Ciancimino, E. and Cannella, S. (2011) 'Supply chain modelling and analysis: an application of Latin square to a repeated coupling of non linear differential equations', International Journal of Logistics Systems and Management, Vol. 9, No. 3, pp.268-279.

Darwish, M.A. and Goyal, S.K. (2011) 'Vendor-managed inventory model for single-vendor single-buyer supply chain', International Journal of Logistics Systems and Management, Vol. 8, No. 3, pp.313-329.

De Kok, A.G. (1993) 'Back-order lead time behaviour in (s;Q)-inventory models with compound renewal demand', Research Report, Graduate School of Industrial Engineering and Management Sciences, Eindhoven University of Technology.

De Kok, T., Janssen, F., Van Doremalen, J., Van Wachem, E., Clerkx, M. and Peeters, W. (2005) 'Philips electronics synchronizes its supply chain to end the bullwhip effect', Interfaces, Vol. 35, No. 1, pp.37-48.

Dejonckheere, J., Disney, S.M., Lambrecht, M.R. and Towill, D.R. (2003) 'Measuring and avoiding the bullwhip effect: a control theoretic approach', European Journal of Operational Research, Vol. 147, No. 3, pp.567-590.

Dejonckheere, J., Disney, S.M., Lambrecht, M.R. and Towill, D.R. (2004) 'The impact of information enrichment on the bullwhip effect in supply chains: a control engineering perspective', European Journal of Operational Research, Vol. 153, No. 3, pp.727-750.

Disney, S.M. and Lambrecht, M.R. (2008) 'On replenishment rules, forecasting, and the bullwhip effect in supply chains', Foundations and Trends in Technology, Information and Operations Management, Vol. 2, No. 1, pp.1-80.

Domínguez Cañizares, R. and Framinan, J.M. (2012) 'Proposal of a multi-agent platform for supply chain-wide order fulfilment', Proceedings of the 4th International Conference on Agents and Artificial Intelligence (ICAART), 6-8 February, Vilamoura, Portugal.

Forrester, J. (1961) Industrial Dynamics, MIT Press, Cambridge, Massachusetts. 
Geary, S., Disney, S.M. and Towill, D.R. (2006) 'On bullwhip in supply chains - historical review, present practice and expected future impact', International Journal of Production Economics, Vol. 101, No. 1, pp.2-18.

Hammond, J.H. (1994) Barilla SpA (A), pp.694-046, Harvard Business School Case.

Hanna, J.B., Skipper, J.B. and Hall, D. (2011) 'Mitigating supply chain disruption: the importance of top management support to collaboration and flexibility', International Journal of Logistics Systems and Management, Vol. 6, No. 4, pp.397-414.

hLättilä, L. (2011) 'Modelling seaports with agent-based modelling and system dynamics', International Journal of Logistics Systems and Management, Vol. 10, No. 1, pp.90-109.

Holweg, M. and Disney, S.M. (2005) 'The evolving frontiers of the bullwhip problem', Paper presented at EurOMA: Operations and Global Competitiveness Conference, 19-22 June, Budapest, Hungary.

Hussain, M. and Drake, P.R. (2011) 'Analysis of the bullwhip effect with order batching in multi-echelon supply chains', International Journal of Physical Distribution and Logistics Management, Vol. 41, No. 8, pp.797-814

Jain, V., Wadhwa, S. and Deshmukh, S.G. (2009) 'Enhancing flexibility in supply chains: modelling random demands and non-stationary supply information', International Journal of Computer Integrated Manufacturing, Vol. 22, No. 8, pp.812-822.

Kaplan, R.S. (1970) 'A dynamic inventory model with stochastic lead times', Management Science Vol. 16, No. 7, pp.491-507.

Keebler, J.S. and Plank, R.E. (2009) 'Logistics performance measurement in the supply chain: A benchmark', Benchmarking, Vol. 16, No. 6, pp.785-798.

Kleijnen, J.P.C. and Smits, M.T. (2003) 'Performance metrics in supply chain management', Journal of the Operational Research Society, Vol. 54, No. 5, pp.507-514.

Lee, H.L., Padmanabhan, V. and Whang, S. (1997) 'Information distortion in a supply chain: the bullwhip effect', Management Science, Vol. 43, No. 4, pp.546-558.

Long, Q., Lin, J. and Sun, Z. (2011) 'Modeling and distributed simulation of supply chain with a multi-agent platform', International Journal of Advanced Manufacturing Technology, Vol. 55, Nos. 9-12, pp.1241-1252.

Magee, J.F (1958) Production Planning and Inventory Control, McGraw-Hill, New York.

Matopoulos, A., Manthou, V. and Vlachopoulou, M. (2007) 'Integrating supply chain operations in the internet era', International Journal of Logistics Systems and Management, Vol. 3, No. 3, pp.305-314.

Nilakantan, K. (2010) 'Enhancing supply chain performance with improved order-control policies', International Journal of Systems Science, Vol. 41, No. 9, pp.1099-1113.

O’Donnell, T., Maguire, L., McIvor, R. and Humphreys, P. (2009) 'Minimizing the bullwhip effect in a supply chain using genetic algorithms', International Journal of Production Research, Vol. 44, No. 8, pp.1523-1543.

Pettersson, A.I. and Segerstedt, A. (2011) 'Performance measurements in supply chains within Swedish industry', International Journal of Logistics Systems and Management, Vol. 9, No. 1, pp.69-88.

Pool, A., Wijngaard, J. and van Der Zee, D-J. (2011) 'Lean planning in the semi-process industry, a case study', International Journal of Production Economics, Vol. 131, No. 1, pp.194-203.

Potter, A. and Disney, S.M. (2006) 'Bullwhip and batching: an exploration', International Journal of Production Economics, Vol. 104, No. 2, pp.408-418.

Reichhart, A., Framiñán, J.M. and Holweg, M. (2008) 'On the link between inventory and responsiveness in multi-product supply chains', International Journal of Systems Science, Vol. 39, No. 7, pp.677-688.

Riddalls, C.E., Bennett, S. and Tipi, N.S. (2000) 'Modelling the dynamics of supply chains', International Journal of Systems Science, Vol. 31, No. 8, pp.969-976. 
Sabato, L. and Bruccoleri, M. (2005) 'The relationship between bullwhip effect and lead times variability in production - distribution networks', Proceedings of VII Convegno A.I.Te.M., 7-9 September, Lecce, Italy.

Sabato, L., Renna, P., Perrone, G., Bruccoleri, M. and La Commare, U. (2004) 'Evaluating the impact of demand and inventory management policies on bullwhip effect in production networks', Proceedings of the ISOMA 2004 9th International Symposium on manufacturing and Applications, 28 June-1 July, Seville, Spain.

Schmenner, R.W. (2001) 'Looking ahead by looking back: swift, even flow in the history of manufacturing', Production and Operations Management, Vol. 10, No. 1, pp.87-96.

Scholz-Reiter, B., Makuschewitz, T., Wirth, F., Schönlein, M., Dashkovskiy, S. and Kosmykov, M. (2011) 'A comparison of mathematical modelling approaches for stability analysis of supply chains', International Journal of Logistics Systems and Management, Vol. 10, No. 2, pp.208-223.

Simon, H.A. (1952) 'On the application of servomechanism theory to the study of production control', Econometrica, Vol. 20, pp.247-268.

Sujatha, R. (2011) 'Role of intelligent agents in facilitating information flow in supply chain management', International Journal of Logistics Systems and Management, Vol. 9, No. 2, pp.229-237.

Syntetos, A.A., Georgantzas, N.C., Boylan, J.E. and Dangerfield, B.C. (2011) 'Judgement and supply chain dynamics', Journal of the Operational Research Society, Vol. 62, No. 6, pp.1138-1158.

Towill, D.R., Zhou, L. and Disney, S.M. (2007) 'Reducing the bullwhip effect: looking through the appropriate lens', International Journal of Production Economics, Vol. 108, Nos. 1-2, pp.444-453.

van der Vorst, J.G.A.J., Tromp, S-O. and van der Zee, D-J. (2009) 'Simulation modelling for food supply chain redesign; integrated decision making on product quality, sustainability and logistics', International Journal of Production Research, Vol. 47, No. 23, pp.6611-6631

Vassian, H.F. (1955) 'Application of discrete variable servo theory to inventory control', Operations Research, Vol. 3, No. 3, pp.272-282.

Wong, W.P. and Wong, K.Y. (2008) 'A review on benchmarking of supply chain performance measures', Benchmarking, Vol. 15, No. 1, pp.25-51.

Yuan, X. and Ashayeri, J. (2009) 'Capacity expansion decision in supply chains: a control theory application', International Journal of Computer Integrated Manufacturing, Vol. 22, No. 4, pp.356-373.

Zhou, L. and Disney, S. (2006) 'Bullwhip and inventory variance in a closed loop supply chain', OR Spectrum, Vol. 28, No. 1, pp.127-149. 